\title{
PASTAGENS ARBORIZADAS NO PROJETO DE ASSENTAMENTO BENFICA, MUNICÍPIO DE ITUPIRANGA, PARÁ, BRASIL ${ }^{1}$
}

\begin{abstract}
Alessio Moreira dos Santos² e Danielle Mitja ${ }^{3}$
RESUMO - Na microrregião de Marabá, PA, as pastagens dos agricultores familiares apresentam alta diversidade de árvores e palmeiras que têm papel importante tanto para limitação da degradação da biodiversidade quanto para suas utilidades. O trabalho foi realizado em 26 propriedades, onde 62 pastagens foram visitadas junto com o agricultor. Em cada pastagem foram repertoriadas todas as árvores e palmeiras presentes. Setenta e uma espécies foram encontradas, pertencentes a 32 famílias, das quais nove se destacaram com maior número de espécies: Caesalpiniaceae (11), Mimosaceae (10), Arecaceae (4), Lecythidaceae (4), Bignoniaceae (3), Fabaceae (3), Moraceae (3), Sapotaceae (3) e Sterculiaceae (3); 20 famílias apresentaram uma única espécie. Vinte e quatro espécies (34\% do total) pertenceram às três famílias Leguminosae (Fabaceae, Caesalpiniaceae e Mimosaceae). As espécies arborescentes são conservadas principalmente em razão dos usos diversos na propriedade. Das 21 espécies, indicadas para arborização de pastagens de agricultores desta e de outras comunidades, nove espécies são particularmente recomendadas pela resistência ao fogo e para muitos anos de pastagem, pelo fato de ter dois usos ou mais: Caryocar villosum (Aubl.) Pers., Bertholletia excelsa H. B. K., Attalea speciosa Mart. ex Spreng., Oenocarpus distichus Mart., Astrocaryum tucuma Mart., Swartzia flaemingii Raddi, Apeiba tibourbou Aubl., Cenostigma tocantinum Ducke e Spondias mombin L.
\end{abstract}

Palavras-chave: Agricultura familiar, Biodiversidade, Resistência ao fogo e Utilidade.

\section{WOODED CATTLE PASTURE IN THE BENFICA SEETLING PROJECT IN ITUPIRANGA, PARÁ, BRAZIL}

\begin{abstract}
In the microregion of Marabá - Pará, the cattle pastures of the family farmers present a high diversity of trees and palm trees which have an important role in limiting biodiversity degradation and for its utilities. The study was carried out in 26 properties, where 62 cattle pastures were visited with the farmer. In each cattle pasture, it was listed all trees and palm trees present in the area. Seventy-one species were found, belonging to 32 families of which 9 were stood out with the greatest number of species: Caesalpiniaceae (11), Mimosaceae (10), Arecaceae (4), Lecythidaceae (4), Bignoniaceae (3), Fabaceae (3), Moraceae (3), Sapotaceae (3) and Sterculiaceae (3); twenty families present one single species. Twenty-four species (34\% of total) belonged to 3 Leguminosae families (Fabaceae, Caesalpiniaceae and Mimosaceae). The tree species are held mainly because of the various uses on the property. Out of the 21 species, suitable for afforestation of cattle pasture of farmers of this and other communities, 9 species are particularly recommended because of their fire resistance and for many years of grazing, and because they have two or more uses: Caryocar villosum (Aubl.) Pers., Bertholletia excelsa H. B. K., Attalea speciosa Mart. ex Spreng., Oenocarpus distichus Mart., Astrocaryum tucuma Mart., Swartzia flaemingii Raddi, Apeiba tibourbou Aubl., Cenostigma tocantinum Ducke, Spondias mombin $L$.
\end{abstract}

Keywords: Biodiversity, Family agriculture, Fire resistance and Utility.

\footnotetext{
${ }^{1}$ Recebido em 09.03.2009 e aceito para publicação em 20.04.2011.

${ }^{2}$ Universidade Federal do Pará, UFPA, Brasil. E-mail: <alessio@ufpa.br>.

${ }^{3}$ Institut de Recherche Pour Le Développement, IRD, França. E-mail: <danielle.mitja@ird.fr>.
} 


\section{INTRODUÇÃO}

A atividade pecuária extensiva na Amazônia nas últimas décadas tornou-se a principal forma de uso da terra. Entre 1975 e 1995, a área de pastagem plantada triplicou, enquanto a área de lavouras aumentou somente 19\% (MARGULIS, 2003). Estima-se que aproximadamente $70 \%$ das pastagens cultivadas localizam-se em propriedades maiores de 1.000 ha. Dessa forma, a implantação de pastagens é considerada responsável por dois terços dos desmatamentos na região (KITAMURA, 1994). O aumento da expansão da atividade tem elevado o índice de desmatamento na Amazônia, resultando em mudança na paisagem devido à conversão de florestas por pastagens (RIBEIRO et al., 2006). Dados do IBGE (2006) sugerem que no Estado do Pará a superfície de pastagens naturais e plantadas (degradadas e em boas condições) chega a 13.167.856 ha, enquanto o efetivo rebanho bovino chega a cerca de 12.807.706 cabeças. Margulis (2003), analisando dados do INPE e do IBAMA de 1999, revelou que na Amazônia Legal os grandes e médios agentes têm maior parcela de responsabilidade pelos desmatamentos. Estimativas feitas no início dos anos de 1990 sugeriram que cerca da metade das áreas de pastagens cultivadas na Amazônia brasileira estavam degradadas ou em processo avançado de degradação (SERRÃO et al., 1993 apud DIAS-FILHO; ANDRADE, 2005). As principais causas da degradação dessas pastagens estão ligadas às práticas inadequadas de pastejo e de manejo das pastagens; falhas no estabelecimento da pastagem; além dos fatores bióticos (doenças e pragas) e abióticos (fertilidade do solo e maior ou menor incidência de chuvas) (DIAS-FILHO, 2005).

As tecnologias de implantação de grande parte das pastagens, o manejo das pastagens e do rebanho na Amazônia ainda são rudimentares (KITAMURA, 1994). Nos projetos de Assentamento do Sudeste Paraense, os pequenos produtores, após curta permanência com lavouras de arroz, milho, mandioca, abacaxi e banana, convertem rapidamente seus plantios em pastagens, fenômeno que tem sido denominado de "pecuarização da pequena propriedade" (ALVES; HOMMA, 2004). Na região de Marabá, Estado do Pará, a principal atividade dos agricultores familiares é a criação extensiva de gado, e seu principal problema é a degradação das pastagens (MITJA; ROBERT, 2003). Trata-se de uma região de fronteira da Amazônia, onde 33\% da área desmatada provém da agricultura familiar e 48\% das fazendas (LASAT, 1998). A agricultura familiar nessa região está distribuída por mais de 300 Projetos de Assentamento, além de outras áreas de posse não legalizada e áreas tituladas (RODRIGUES, 2005).

$\mathrm{Na}$ área do projeto de assentamento Benfica, localizada no Município de Itupiranga, PA, os agricultores (Agricultura familiar) seguem a tendência da produção bovina na área de fronteira, as pastagens cobrem cerca de $70 \%$ da área do assentamento e a principal espécie cultivada é a Bachiaria brizantha cv. Marandu (REIS, 2006). Diante das condições de degradação de grande parte das pastagens cultivadas e dos poucos recursos que esses agricultores têm para investir na recuperação e renovação dessas pastagens, pelo uso de implementos agrícolas e adubos (FRANKE, 1999), o aumento da presença de árvores nas pastagens, com espécies nativas que crescem naturalmente nesses ambientes, seria uma alternativa para a recuperação dessas áreas, além de trazer vários outros benefícios com o uso dessas árvores.

Segundo Castro et al. (1996), apesar de a associação entre árvores e pastagens ainda não ser prática generalizada, as árvores exercem uma série de efeitos benéficos sobre o ecossistema das pastagens que devem ser considerados, principalmente nos sistemas extensivos e semi-intensivos. Nesse sentido, a leguminosa arbórea é uma opção pouco lembrada para incorporação de nitrogênio ao ecossistema da pastagem (ANDRADE et al., 2002). Evangelista e Lima (2006) relataram que, com a busca de sistemas autossustentáveis, passou-se a valorizar os bons efeitos (dependendo da densidade e da espécie) proporcionados pelas árvores nas pastagens, tanto para as forrageiras quanto para os animais.

\section{MATERIAL E MÉTODOS}

\section{1. Área de estudo}

A área estudada está localizada no Município de Itupiranga (microrregião de Marabá, PA), tem como sede a Vila Santa Izabel, cujas coordenadas geográficas são S 50 14'54"' e W 49 50'26"', encontra-se a 122 km da cidade de Marabá e a 74 km da cidade de Itupiranga, no km-15 da vicinal Rio da Esquerda. O principal acesso é por estrada de terra batida, ligando o Projeto de Assentamento Benfica (PA-Benfica) à rodovia Transamazônica (REIS, 2006).

O clima é o Tropical Chuvoso de Selva Isotérmico (Afi), com precipitações anuais em torno de 1.925,7 mm, e a temperatura média anual é de $28,0^{\circ} \mathrm{C}$, com máximas de $32,7^{\circ} \mathrm{C}$ e mínimas de $23,3^{\circ} \mathrm{C}$ (ALMEIDA, 2007).

Revista Árvore, Viçosa-MG, v.35, n.4., p.919-930, 2011 
Os solos predominantes são Latossolos Amarelos com textura argilosa, com pequenas quantidades de solos lateríticos, com boa drenagem, profundos e baixa fertilidade natural.

\subsection{Métodos de levantamento de campo e tratamento das amostras}

O trabalho foi realizado em 26 propriedades, na área do PA-Benfica, Município de Itupiranga, onde 62 pastagens foram visitadas junto com os agricultores nos anos de 2005 e 2006.

Por meio de entrevistas com os agricultores pesquisados, registraram-se para cada espécie coletada seu nome vernacular e as utilidades, assim como as informações relativas à implantação da pastagem, a data das limpezas e a data dos fogos. Na coleta, foram consideradas as árvores e palmeiras com CAP (Circunferência à Altura do Peito) acima de $20 \mathrm{~cm}$. Cinco exsicatas de cada espécie foram coletadas para futura identificação botânica no Herbário do Museu Paraense Emílio Goeldi (MPEG), em Belém, PA.

Para fins de análise das espécies encontradas, foi feito o cálculo das frequências absolutas (número de pastagens onde se encontram as espécies) e frequência relativa das espécies (a frequência absoluta dividida pelo número total de pastagens amostradas).

\section{RESULTADOS E DISCUSSÃO}

\subsection{As espécies lenhosas das pastagens}

Nas 62 pastagens das 26 propriedades representando 487 ha, foram encontradas 32 famílias, das quais quatro se destacaram com maior número de espécies: Caesalpiniaceae (11), Mimosaceae (10), Arecaceae (5) e Lecythidaceae (4). Vinte famílias apresentaram uma única espécie. No total, 2.109 indivíduos e 71 espécies foram encontrados. As três espécies com maior número de indivíduos foram: Attalea speciosa (1218), Cenostigma tocantinum (113) e Cassia fastuosa (87). Vinte e sete espécies foram representadas por somente um ou dois indivíduos. A riqueza específica observada nas pastagens de Benfica foi inferior às 199 espécies encontradas num estudo semelhante conduzido pela Embrapa Acre (FRANKE, 1999), onde foram estudadas as pastagens de 25 propriedades, ou em Monteverde - Costa Rica (HARVEY; HABER, 1999), onde, numa área de 237 ha de pastagens de 24 agricultores, foram encontradas 5.583 indivíduos de 190 espécies e 56 famílias. Destacando-se, neste último trabalho, as famílias Lauraceae (28 sp), Myrtaceae (17 sp) e Fabaceae (15 sp).

Em Benfica, 24 espécies, ou seja, 34\% do total das espécies pertencem às três famílias leguminosae: Fabaceae (3 espécies), Caesalpiniaceae (11 sp) e Mimosaceae (10 sp). Esse resultado é maior em proporção do número de espécies do que o obtido no estudo sobre as pastagens do Acre (FRANKE, 1999), que apresentou 19\% (38 sp) do total das espécies pertencentes às três famílias leguminosae: Fabaceae (10), Caesalpiniaceae (10 sp) e Mimosaceae (18 sp). Da mesma forma, ocorre no estudo das pastagens da Costa Rica, cujo destaque é somente a família Fabaceae (15 sp), entre as famílias leguminosae. Segundo Jesus et al. (2005), as espécies leguminosae têm grande capacidade para reabilitação de áreas degradadas.

\subsection{Utilidade das espécies}

As árvores e palmeiras no interior das pastagens dos agricultores são utilizadas das mais variadas formas: para fins medicinais, alimentícios (humanos e fauna) e artesanais, assim como serve para fazer carvão e estaca e fornecer sombra, madeira, lenha e palha (Tabela 1). Os pequenos agricultores geralmente conhecem, usam e aproveitam as espécies presentes nas pastagens. Para Pinheiro et al. (2005), alguns usos estão diretamente relacionados à atividade principal dos moradores (pesca, agricultura ou extrativismo). A preferência dos agricultores foi por espécies que proporcionam benefícios múltiplos, em detrimento daquelas caracterizadas por um uso único. O uso múltiplo das espécies é interessante, pois se constitui em mais uma forma de colaboração na renda da propriedade (RIBEIRO et al., 1994).

Os 25 agricultores entrevistados forneceram um total de 496 respostas sobre os usos que fazem das árvores e palmeiras em suas pastagens. Os tipos de usos das plantas mais citados pelos agricultores foram: sombra para o gado (161 respostas), frutos para alimentação humana (91 respostas) e utilização da madeira (81 respostas). As principais espécies que providenciam sombra foram Attalea maripa, Bertholletia excelsa, Cenostigma tocantinum e Cassia fastuosa. As drásticas condições climáticas regionais, que causam estresse no rebanho e queda na produção explicam porque o principal uso citado foi o fornecimento de sombra, esta proporciona a redução da insolação e da temperatura ambiente (VEIGA et al., 2000).

Revista Árvore, Viçosa-MG, v.35, n.4, p.919-930, 2011 


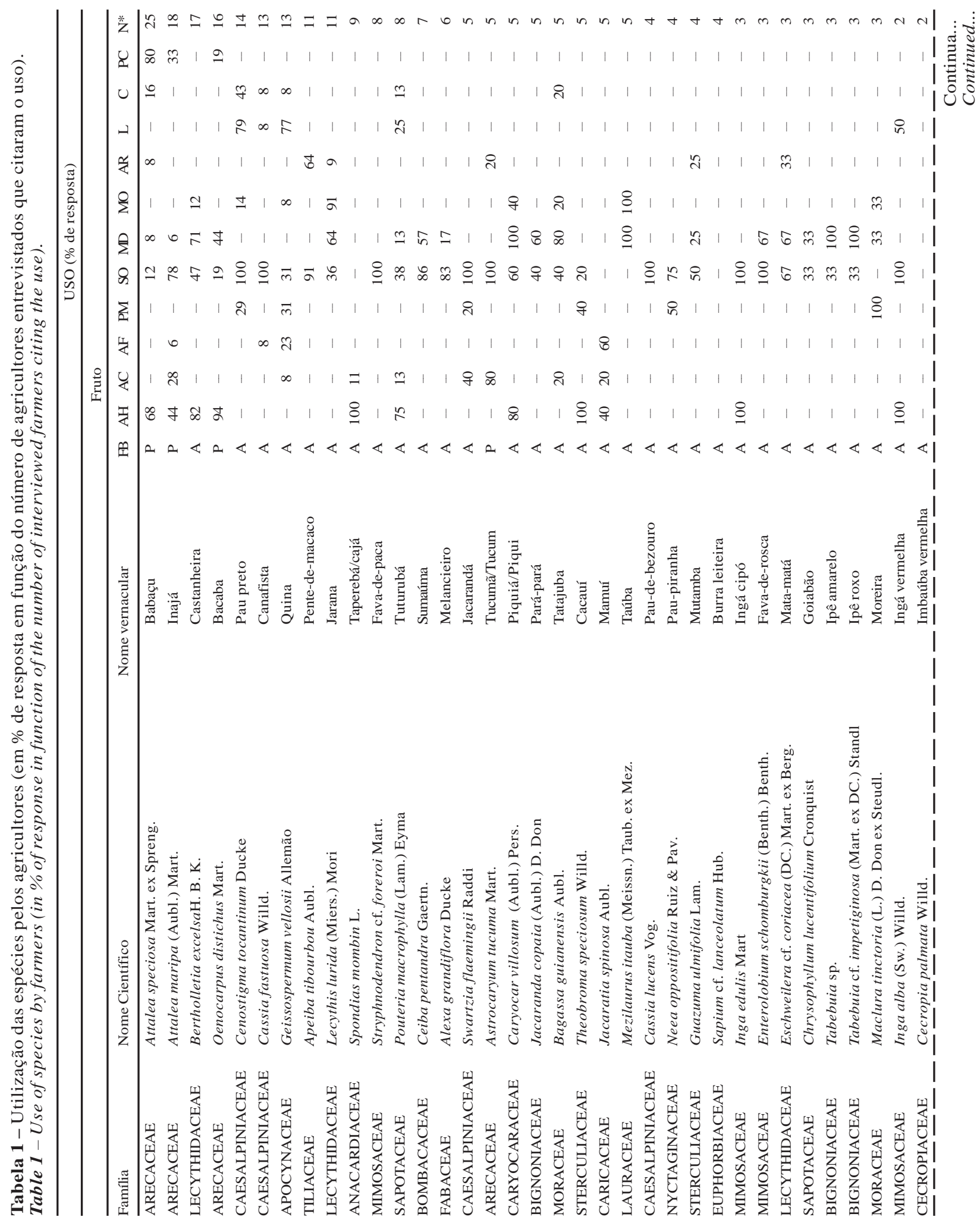

Revista Árvore, Viçosa-MG, v.35, n.4., p.919-930, 2011 


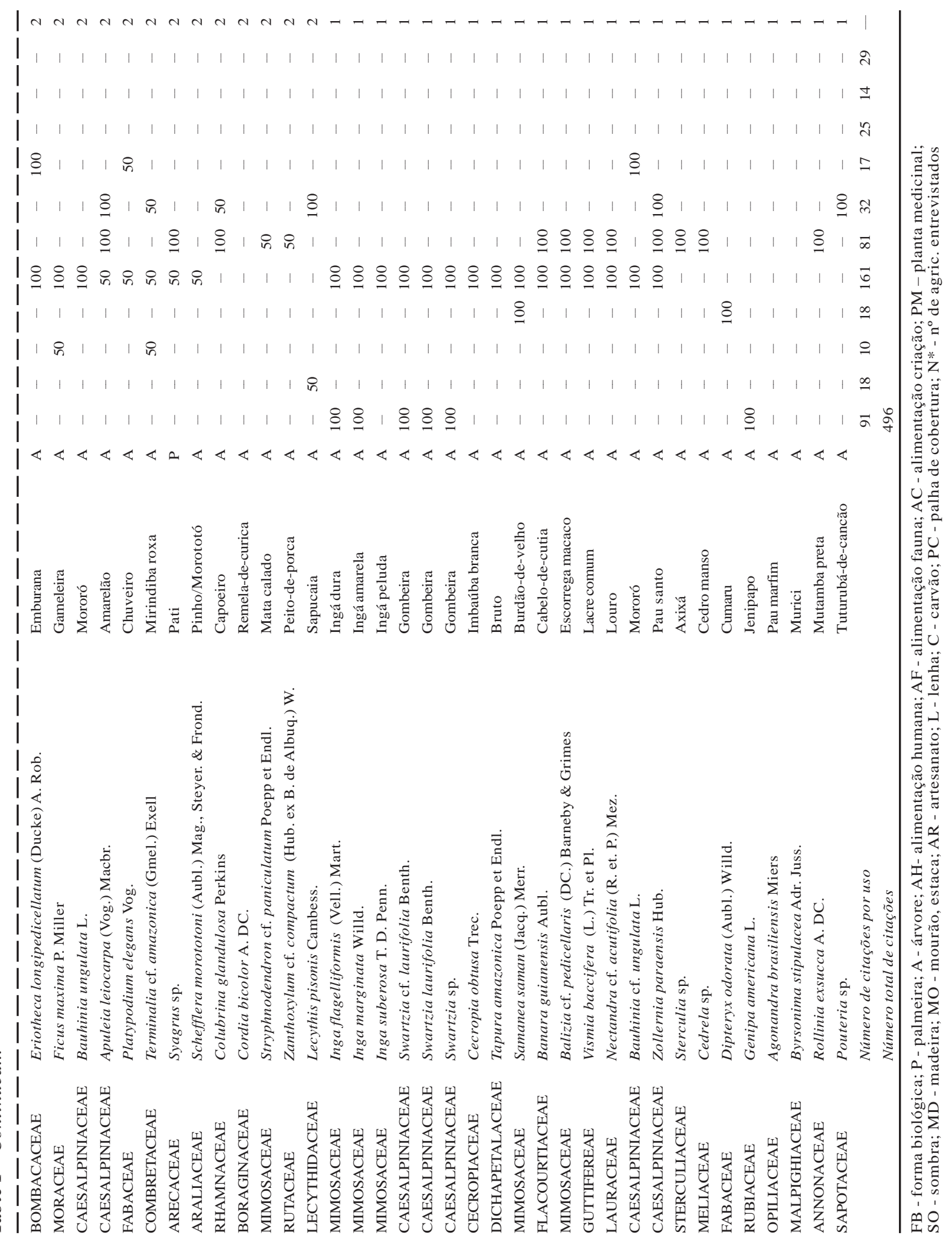


As espécies cujo fruto é utilizado para alimentação humana, seja "in natura” ou seus subprodutos (azeites e óleos) extraídos dos frutos foram: Attalea speciosa, Attalea maripa, Bertholletia excelsa e Oenocarpus distichus. Um estudo sobre espécies vegetais úteis regionais da baixada maranhense (PINHEIRO et al., 2005) mostrou que a palmeira babaçu (Attalea speciosa) aparece como a de mais freqüente utilização, com destaque para o fruto, que tem grande utilização principalmente como alimento, ao mesmo tempo em que gera renda, como produto comercial. A sustentabilidade estará vinculada à capacidade de os agricultores conservarem ou aumentarem sua qualidade de vida mantendo e garantindo recursos para as próximas gerações (GOMES, 2004).

Os agricultores utilizam também a madeira de diversas espécies para construir casas e currais. As principais espécies destinadas a esse fim são: Bertholletia excelsa, Oenocarpus distichus e Lecythis lurida. A agricultura familiar tem necessidade de usar matéria-prima do próprio lote para construções, confecção de utensílios e ferramentas a baixo custo. O potencial madeireiro de algumas espécies colabora para que ocorra a venda da madeira visando à complementação da renda. Para Michelotti e Rodrigues (2004), a Floresta Amazônica é dinâmica e complexa, sua preservação não pode ser sinônimo de intocabilidade e é preciso que haja maior interação entre a biodiversidade e a sociodiversidade regional de forma sustentável. Deve-se deixar de considerar a sustentabilidade ecológica da agricultura familiar apenas em função da área de florestas primárias.

\subsection{Tipologia de pastagens em relação ao fogo}

Levando-se em consideração os tipos de pastagens quanto à idade e ao número de fogos praticados, foi elaborada uma tipologia para agrupar pastagens com categorias idade/fogo semelhantes. Para cada um dos tipos, obteve-se a lista de lenhosos presentes. Os tipos identificados foram:

- Tipo 1: SQ “Pastagens sem queima”: Pastagens de 1 a 4 anos sem o uso do fogo.

- Tipo 2: L "Pastagens com intervalos de queima longos": Pastagens com um fogo a cada cinco anos ou mais.

- Tipo 3: M "Pastagens com intervalos de queima moderados": Pastagens com um fogo a cada três a quatro anos.

- Tipo 4: C “Pastagens com intervalos de queima curtos”: Pastagens com um fogo a cada um a 2,5 anos.

Desse modo, o tipo 4, no qual as queimadas foram mais frequentes, compreendeu 55,3\% das pastagens amostradas, seguido do tipo 3 (32,2\%), tipo 1 (8\%) e tipo 2 (6,5\%) (Tabela 2). As pastagens sem queima apresentaram a segunda maior densidade de espécies encontradas $(0,47)$, são pastagens ainda sem nenhuma queima e de até 4 anos de idade (pastagens novas). Nesse caso, a riqueza de espécies do levantamento não foi maior porque alguns indivíduos de espécies presentes não atingiram a circunferência mínima para serem contabilizados (CAP > $20 \mathrm{~cm}$ ). Os intervalos longos entre os fogos favoreceram a conservação das espécies nas pastagens, chegando aos maiores valores observados de 0,69 espécies por hectare. À medida que o intervalo das queimadas foi diminuindo, houve diminuição também da densidade das espécies, fato igualmente observado por Heringer e Jacques (2001). A mesma dinâmica ocorreu com a média das idades das pastagens e com o número de indivíduos por hectare (Tabela 2).

Tabela 2 - Número de espécies e indivíduos encontrados por hectare em cada um dos tipos identificados. Table 2 - Number of species and individuals found per hectare in each of the types identified.

\begin{tabular}{|c|c|c|c|c|}
\hline Tipos & $\begin{array}{c}(1) \quad \text { SQ } \\
\text { Sem queima }\end{array}$ & $\begin{array}{cl}(2) & \mathrm{L} \\
\text { Intervalo longo }\end{array}$ & $\begin{array}{cc}(3) & \mathrm{M} \\
\text { Intervalo moderado }\end{array}$ & $\begin{array}{cl}\text { (4) } & \mathrm{C} \\
\text { Intervalo } & \text { curto } \\
\end{array}$ \\
\hline Porcentagem $/ \mathrm{n}^{\circ}$ de pastagens & $8 \% / 5$ & $6,5 \% \quad / \quad 4$ & $32,2 \% \quad / \quad 20$ & $53,3 \%$ / 33 \\
\hline Área amostrada (ha) & 36,3 & 21,78 & 126,42 & 302,67 \\
\hline Limpezas (média) & 0,4 & 5,8 & 5,4 & 5,2 \\
\hline$N^{\circ}$ espécies & 17 & 15 & 47 & 50 \\
\hline Espécies/ha & 0,47 & 0,69 & 0,37 & 0,17 \\
\hline Média das idades das pastagens (ano) & 1,6 & 10,75 & 7,9 & 5,73 \\
\hline Número de indivíduos/ha & 3,36 & 7,76 & 6,14 & 3,44 \\
\hline
\end{tabular}

Revista Árvore, Viçosa-MG, v.35, n.4., p.919-930, 2011 


\subsection{Distribuição das espécies em função das classes de fogo}

As maiores densidades de indivíduos foram encontradas em pastagens onde aconteceram de 6 a 10 fogos com 6,11 indivíduos/ha. Seguidos das pastagens de classe de 0 a 2 fogos com 5,55 indivíduos/ha e por último, as pastagens de 3 a 5 fogos que apresentaram as menores densidades de indivíduos com 2,98 indivíduos/ha (Tabela 3). Segundo Heringer e Jacques (2001), a sobrevivência das plantas à queima está relacionada com a integridade do tecido cambial do caule e raiz, assim como o diâmetro e altura dos indivíduos (MEDEIROS; MIRANDA, 2005). Foram encontradas 18 espécies exclusivamente em pastagens com classe de 0 - 2 fogos, como: Lecythis pisonis, Maclura tinctoria e Platypodium elegans. Vinte e quatro espécies presentes nas duas primeiras classes de fogo não existem mais depois de cinco fogos, entre elas: Stryphnodendron cf. foreroi, Bagassa guianensis e Colubrina glandulosa. Dezessete espécies estavam presentes em todas as classes de fogos, resistindo até 10 fogos (Tabela 3).

Algumas espécies presentes em todas as classes de fogo aumentam sua densidade conforme o número de fogos aplicados vai aumentando, como: Cassia fastuosa, Geissospermum vellosii e Spondias mombin (Tabela 3). Outras espécies têm sua densidade conservada conforme o aumento do número de fogos: Bertholletia excelsa, Lecythis lurida, Attalea speciosa e Astrocaryum tucuma, enquanto outras espécies veem sua densidade diminuir: Oenocarpus distichus, Cenostigma tocantinum e Apeiba tibourbou. Há ainda espécies que aparecem em pastagens com classe de três a cinco fogos e depois desaparecem com o aumento do número de fogos: Inga edulis, Eriotheca longipedicellatum e Byrsonima stipulacea. Conforme a intensificação do uso do fogo, o tempo de recuperação desses indivíduos vai diminuir e, consequentemente, a densidade de indivíduos tende a cair, salvo aquelas espécies que possuem capacidade de adaptação.

O fogo propicia a eliminação de algumas espécies, mas pode também favorecer o desenvolvimento de outras espécies. Segundo Shanley e Medina (2005), os fogos anuais estimulam a germinação das sementes das palmeiras. No entanto, deve-se ressaltar que esses efeitos benéficos ocorrem em algumas espécies, em geral os danos causados pelo fogo podem, de acordo com Heringer e Jacques (2001), comprometer diretamente o crescimento, sobrevivência e reprodução das plantas. Um experimento de germinação de sementes de babaçu (MITJA; FERRAZ, 2001) mostrou que as sementes de babaçu são destruídas pelo fogo, mas que o enterramento dos frutos, que acontece nas pastagens pelo pisoteio do rebanho, protege as sementes e favorece a germinação.

\subsection{Densidade de indivíduos em função da idade das pastagens}

A idade das pastagens amostradas varia de 1 a 31 anos. Adensidade de algumas espécies aumenta conforme a pastagem vai ficando mais velha: Attalea speciosa, Apeiba tibourbou e Attalea maripa (Tabela 4). As espécies encontradas nas pastagens mais antigas são aquelas que geralmente não dependem do ambiente da floresta para se manter e se desenvolver. Shanley e Medina (2005) descreveram também o caso das palmeiras, que podem possuir maiores densidades em áreas abertas do que propriamente nas matas.

Outras espécies, também presentes em todas as faixas etárias, diminuem sua densidade conforme a pastagem vai ficando mais antiga: Bertholletia excelsa, Oenocarpus distichus e Cenostigma tocantinum. Outras não existem nas pastagens de mais de 10 anos, por exemplo: Cassia fastuosa, Stryphnodendron cf. foreroi e Theobroma speciosum (Tabela 4).

Há ainda espécies que estão presentes nas pastagens apenas nos primeiros anos (1 a 5 anos): Stryphnodendron cf. paniculatum, Swartzia sp. e Tapura amazônica. E outras que aparecem somente quando a pastagem atinge idade intermediária (5 a 10 anos), desaparecendo logo em seguida, como: Colubrina glandulosa, Guazuma ulmifolia e Inga suberosa. Ao contrário daquelas espécies que diminuem a densidade quando a pastagem fica antiga, existem espécies mais dependentes da floresta.

Veiga et al. (2000), citando a castanheira (Bertholletia excelsa), revelaram que quando submetida ao ecossistema das pastagens essa espécie frequentemente é derrubada pelos ventos, ficando com a sustentação comprometida devido à ausência de outras árvores da floresta ao seu redor, mesmo assim essa espécie foi encontrada neste trabalho dentro das oito espécies com maior número de indivíduos.

As espécies com maior densidade de indivíduos nas pastagens de Benfica: Attalea speciosa, Cenostigma tocantinum, Cassia fastuosa, Apeiba tibourbou, Attalea 
Tabela 3 - Distribuição dos indivíduos de cada espécie em função das diferentes classes de fogo.

Table 3 -Distribution of individuals of each species in function of different fire classes.

\begin{tabular}{|c|c|c|c|c|}
\hline $\begin{array}{l}\text { Classes de fogos } \\
\text { Número de pastos } \\
\text { Superfície (Ha) }\end{array}$ & $\begin{array}{c}0 \text { а } 2 \\
37 \\
234,43 \\
\end{array}$ & $\begin{array}{c}3 \text { a } 5 \\
22 \\
230,96 \\
\end{array}$ & $\begin{array}{c}6 \text { a } 10 \\
3 \\
21,78 \\
\end{array}$ & $\begin{array}{l}\text { Quantidade } \\
\text { total de } \\
\text { indivíduos }\end{array}$ \\
\hline \multicolumn{5}{|l|}{ Espécies } \\
\hline Lecythis pisonis & 0,05 & - & - & 12 \\
\hline Maclura tinctoria & 0,02 & - & - & 5 \\
\hline Platypodium elegans & 0,01 & - & - & 4 \\
\hline Samanea saman & 0,01 & - & - & 4 \\
\hline Cordia bicolor & 0,01 & - & - & 3 \\
\hline Sterculia sp. & 0,01 & - & - & 1 \\
\hline Tapura amazonica & 0,01 & - & - & 1 \\
\hline Banara guianensis & 0,01 & - & - & 1 \\
\hline Dipteryx odorata & 0,01 & - & - & 1 \\
\hline Vismia baccifera & 0,01 & - & - & 1 \\
\hline Nectandra cf. acutifolia & 0,01 & - & - & 1 \\
\hline Rollinia exsucca & 0,01 & - & - & 1 \\
\hline Zollernia paraensis & 0,01 & - & - & 1 \\
\hline Bauhinia ungulata var - obtusifolia & 0,01 & - & - & 1 \\
\hline Cecropia obtusa & 0,01 & - & - & 1 \\
\hline Swartzia cf. Laurifolia & 0,01 & - & - & 1 \\
\hline Swartzia laurifolia & 0,01 & - & - & 1 \\
\hline Inga flagelliformis & 0,01 & - & - & 1 \\
\hline Stryphnodendron cf. foreroi & 0,05 & 0,16 & - & 50 \\
\hline Bagassa guianensis & 0,01 & 0,07 & - & 19 \\
\hline Colubrina glandulosa & 0,01 & 0,03 & - & 9 \\
\hline Sapium cf. lanceolatum & 0,01 & 0,02 & - & 7 \\
\hline Attalea maripa & 0,19 & 0,15 & - & 78 \\
\hline Theobroma speciosum & 0,10 & 0,01 & - & 24 \\
\hline Cassia lucens & 0,02 & 0,01 & - & 9 \\
\hline Pouteria macrophylla & 0,02 & 0,01 & - & 9 \\
\hline Jacaratia spinosa & 0,02 & 0,01 & - & 8 \\
\hline Mezilaurus itauba & 0,03 & 0,004 & - & 8 \\
\hline Alexa grandiflora & 0,01 & 0,01 & - & 7 \\
\hline Guazuma ulmifolia & 0,02 & 0,004 & - & 7 \\
\hline Zanthoxylum cf. compactum & 0,02 & 0,01 & - & 7 \\
\hline Tabebuia cf. impetiginosa & 0,01 & 0,01 & - & 6 \\
\hline Inga alba & 0,01 & 0,01 & - & 4 \\
\hline Enterolobium schomburgkii & 0,02 & 0,004 & - & 6 \\
\hline Tabebuia sp. & 0,01 & 0,004 & - & 5 \\
\hline Syagrus sp. & 0,01 & 0,004 & - & 3 \\
\hline Cecropia palmata & 0,01 & 0,004 & - & 2 \\
\hline Bauhinia cf. ungulata & 0,01 & 0,004 & - & 2 \\
\hline Apuleia leiocarpa & 0,01 & 0,004 & - & 2 \\
\hline Stryphnodendron cf. paniculatum & 0,01 & 0,004 & - & 2 \\
\hline Terminalia cf. amazonica & 0,01 & 0,004 & - & 2 \\
\hline Schefflera morototoni & 0,01 & 0,004 & - & 2 \\
\hline Caryocar villosum & - & 0,02 & 0,18 & 9 \\
\hline Cassia fastuosa & 0,16 & 0,15 & 0,73 & 87 \\
\hline Geissospermum vellosii & 0,04 & 0,03 & 0,18 & 23 \\
\hline Spondias mombin & 0,04 & 0,05 & 0,14 & 23 \\
\hline Swartzia flaemingii & 0,01 & 0,004 & 0,09 & 6 \\
\hline Neea oppositifolia & 0,01 & 0,02 & 0,05 & 8 \\
\hline Inga edulis & 0,01 & 0,02 & 0,05 & 7 \\
\hline Chrysophyllum lucentifolium & 0,01 & 0,004 & 0,05 & 3 \\
\hline Eschweilera cf. coriacea & 0,01 & 0,004 & 0,05 & 3 \\
\hline Bertholletia excelsa & 0,15 & 0,04 & 0,18 & 47 \\
\hline Lecythis lurida & 0,07 & 0,02 & 0,05 & 23 \\
\hline Attalea speciosa & 3,40 & 1,45 & 3,9 & 1218 \\
\hline Astrocaryum tucuma & 0,07 & 0,01 & 0,05 & 20 \\
\hline Oenocarpus distichus & 0,16 & 0,12 & 0,05 & 65 \\
\hline Cenostigma tocantinum & 0,26 & 0,22 & 0,05 & 113 \\
\hline Apeiba tibourbou & 0,23 & 0,09 & 0,18 & 78 \\
\hline Ceiba pentandra & 0,04 & 0,04 & 0,05 & 18 \\
\hline Jacaranda copaia & 0,04 & 0,01 & 0,05 & 13 \\
\hline Inga suberosa & - & 0,03 & - & 7 \\
\hline Eriotheca longipedicellatum & - & 0,03 & - & 6 \\
\hline Byrsonima stipulacea & - & 0,01 & - & 3 \\
\hline Ficus maxima & - & 0,01 & - & 2 \\
\hline Swartzia sp. & - & 0,01 & - & 2 \\
\hline Genipa americana & - & 0,004 & - & 1 \\
\hline Balizia cf. pedicellaris & - & 0,004 & - & 1 \\
\hline Agonandra brasiliensis & - & 0,004 & - & 1 \\
\hline Inga marginata & - & 0,004 & - & 1 \\
\hline Cedrela sp. & - & 0,004 & - & 1 \\
\hline Pouteria sp. & - & - & 0,05 & 1 \\
\hline Total & 5,55 & 2,98 & 6,11 & 2109 \\
\hline
\end{tabular}

Revista Árvore, Viçosa-MG, v.35, n.4., p.919-930, 2011 
Tabela 4 - Densidade de indivíduos das espécies em função da classe das pastagens (indivíduo/ha). Table 4 -Density of individuals of the species in function of pasture classes (individual/ha).

\begin{tabular}{|c|c|c|c|}
\hline \multirow[b]{2}{*}{ Espécies } & \multicolumn{3}{|c|}{ Idade das pastagens (anos) } \\
\hline & 1 a 5 & 5 a 10 & $>10$ \\
\hline Attalea speciosa & 1,62 & 2,76 & 9,5 \\
\hline Apeiba tibourbou & 0,17 & 0,14 & 0,35 \\
\hline Attalea maripa & 0,16 & 0,15 & 0,35 \\
\hline Astrocaryum tucuma & 0,02 & 0,04 & 0,24 \\
\hline Caryocar villosum & - & 0,02 & 0,24 \\
\hline Spondias mombin & 0,02 & 0,07 & 0,12 \\
\hline Swartzia flaemingii & 0,005 & 0,02 & 0,06 \\
\hline Alexa grandiflora & 0,01 & 0,02 & 0,06 \\
\hline Cenostigma tocantinum & 0,09 & 0,36 & 0,06 \\
\hline Bertholletia excelsa & 0,1 & 0,1 & 0,06 \\
\hline Oenocarpus distichus & 0,18 & 0,1 & 0,06 \\
\hline Cassia fastuosa & 0,09 & 0,27 & - \\
\hline Stryphnodendron cf. foreroi & 0,06 & 0,15 & - \\
\hline Theobroma speciosum & 0,06 & 0,05 & - \\
\hline Lecythis lurida & 0,06 & 0,04 & - \\
\hline Geissospermum vellosii & 0,05 & 0,05 & - \\
\hline Bagassa guianensis & 0,03 & 0,05 & - \\
\hline Pouteria macrophylla & 0,03 & 0,01 & - \\
\hline Mezilaurus itauba & 0,02 & 0,01 & - \\
\hline Lecythis pisonis & 0,02 & 0,03 & - \\
\hline Enterolobium schomburgkii & 0,02 & 0,01 & - \\
\hline Eriotheca longipedicellatum & 0,02 & 0,01 & - \\
\hline Jacaranda copaia & 0,01 & 0,04 & - \\
\hline Jacaratia spinosa & 0,01 & 0,02 & - \\
\hline Maclura tinctoria & 0,01 & 0,01 & - \\
\hline Neea oppositifolia & 0,01 & 0,02 & - \\
\hline Cassia lucens & 0,01 & 0,03 & - \\
\hline Schefflera morototoni & 0,005 & 0,004 & - \\
\hline Cecropia palmata & 0,005 & 0,004 & - \\
\hline Ceiba pentandra & 0,005 & 0,07 & - \\
\hline Sapium cf. lanceolatum & 0,005 & 0,02 & - \\
\hline Inga edulis & 0,005 & 0,02 & - \\
\hline Zanthoxylum cf. compactum & 0,005 & 0,02 & - \\
\hline Tabebuia cf. impetiginosa & 0,005 & 0,02 & - \\
\hline Inga alba & 0,005 & 0,01 & - \\
\hline Cordia bicolor & 0,005 & 0,01 & - \\
\hline Eschweilera cf. coriacea & 0,005 & 0,01 & - \\
\hline Chrysophyllum lucentifolium & 0,005 & 0,01 & - \\
\hline Apuleia leiocarpa & 0,005 & 0,004 & - \\
\hline Stryphnodendron cf. paniculatum & 0,01 & - & - \\
\hline Swartzia sp. & 0,01 & - & - \\
\hline Tapura amazonica & 0,005 & - & - \\
\hline Nectandra cf. acutifolia & 0,005 & - & - \\
\hline Sterculia sp. & 0,005 & - & - \\
\hline Inga flagelliformis & 0,005 & - & - \\
\hline Colubrina glandulosa & - & 0,03 & - \\
\hline Guazuma ulmifolia & - & 0,03 & - \\
\hline Inga suberosa & - & 0,03 & - \\
\hline Tabebuia sp. & - & 0,02 & - \\
\hline Platypodium elegans & - & 0,02 & - \\
\hline Samanea saman & - & 0,02 & - \\
\hline Byrsonima stipulacea & - & 0,01 & - \\
\hline Syagrus sp. & - & 0,01 & - \\
\hline Terminalia cf. amazonica & - & 0,01 & - \\
\hline Bauhinia cf. ungulata & - & 0,01 & - \\
\hline Ficus maxima & - & 0,01 & - \\
\hline Bauhinia ungulata var - obtusifolia & - & 0,004 & - \\
\hline Swartzia cf. laurifolia & - & 0,004 & - \\
\hline Dipteryx odorata & - & 0,004 & - \\
\hline Banara guianensis & - & 0,004 & - \\
\hline Balizia cf. pedicellaris & - & 0,004 & - \\
\hline Agonandra brasiliensis & - & 0,004 & - \\
\hline Cedrela sp. & - & 0,004 & - \\
\hline Genipa americana & - & 0,004 & - \\
\hline Vismia baccifera & - & 0,004 & - \\
\hline Cecropia obtusa & - & 0,004 & - \\
\hline Inga marginata & - & 0,004 & - \\
\hline Rollinia exsucca & - & 0,004 & - \\
\hline Zollernia paraensis & - & 0,004 & - \\
\hline Pouteria sp. & - & 0,004 & - \\
\hline Swartzia laurifolia & - & 0,004 & - \\
\hline Superfície (ha) & 210,41 & 259,82 & 16,94 \\
\hline Número de indivíduos por ha & 2,98 & 4,98 & 11,1 \\
\hline
\end{tabular}


Tabela 5 - Lista de espécies indicadas para arborização de pastagens.

Table 5 - List of species indicated for cattle pasture afforestation.

\begin{tabular}{|c|c|c|c|c|c|c|c|c|c|c|}
\hline \multirow[t]{2}{*}{ Espécies indicadas } & \multicolumn{4}{|c|}{ Utilidades } & \multicolumn{3}{|c|}{ Classes de fogo } & \multicolumn{3}{|c|}{ Pastagens (ano) } \\
\hline & Sombra & Fruto & Mad. & Total & 0 a 2 & 3 a 5 & 6 a 10 & 1 a 5 & 5 a 10 & $>10$ \\
\hline Piquiá (Caryocar villosum) & $\mathrm{X}$ & $\mathrm{X}$ & $\mathrm{X}$ & 4 & - & - & $\mathrm{X}$ & - & - & $X$ \\
\hline Castanheira (Bertholletia excelsa) & $\mathrm{X}$ & $\mathrm{X}$ & $\mathrm{X}$ & 4 & - & - & $\mathrm{X}$ & - & - & $\mathrm{X}$ \\
\hline Babaçu (Attalea speciosa) & $\mathrm{X}$ & $X$ & $X$ & 6 & - & - & $\mathrm{X}$ & - & - & $X$ \\
\hline Bacaba (Oenocarpus distichus) & $\mathrm{X}$ & $\mathrm{X}$ & $\mathrm{X}$ & 4 & - & - & $\mathrm{X}$ & - & - & $\mathrm{X}$ \\
\hline Tucumã (Astrocaryum tucuma) & $\mathrm{X}$ & $\mathrm{X}$ & - & 3 & - & - & $\mathrm{X}$ & - & - & $\mathrm{X}$ \\
\hline Jacarandá (Swartzia flaemingii) & $\mathrm{X}$ & $\mathrm{X}$ & - & 3 & - & - & $\mathrm{X}$ & - & - & $\mathrm{X}$ \\
\hline Pente-de-macaco (Apeiba tibourbou) & $\mathrm{X}$ & - & - & 2 & - & - & $\mathrm{X}$ & - & - & $\mathrm{X}$ \\
\hline Pau-preto (Cenostigma tocantinum) & $\mathrm{X}$ & - & - & 5 & - & - & $\mathrm{X}$ & - & - & $\mathrm{X}$ \\
\hline Taperebá (Spondias mombin) & - & $\mathrm{X}$ & - & 2 & - & - & $\mathrm{X}$ & - & - & $\mathrm{X}$ \\
\hline Quina (Geissospermum vellosii) & $X$ & - & - & 7 & - & - & $\mathrm{X}$ & - & $\mathrm{X}$ & - \\
\hline Pau-piranha (Neea oppositifolia) & $\mathrm{X}$ & - & - & 2 & - & - & $\mathrm{X}$ & - & $\mathrm{X}$ & - \\
\hline Mata-matá (Eschweilera cf. coriacea) & $\mathrm{X}$ & - & $\mathrm{X}$ & 3 & - & - & $\mathrm{X}$ & - & $\mathrm{X}$ & - \\
\hline Goiabão (Chrysophyllum lucentifolium) & $\mathrm{X}$ & - & $X$ & 2 & - & - & $\mathrm{X}$ & - & $\mathrm{X}$ & - \\
\hline Jarana (Lecythis lurida) & $\mathrm{X}$ & - & $\mathrm{X}$ & 4 & - & - & $\mathrm{X}$ & - & $\mathrm{X}$ & - \\
\hline Pará-pará (Jacaranda copaia) & $\mathrm{X}$ & - & $\mathrm{X}$ & 2 & - & - & $\mathrm{X}$ & - & $\mathrm{X}$ & - \\
\hline Sumaúma (Ceiba pentandra) & $\mathrm{X}$ & - & - & 2 & - & - & $\mathrm{X}$ & - & $\mathrm{X}$ & - \\
\hline Canafista (Cassia fastuosa) & $\mathrm{X}$ & - & - & 4 & - & - & $\mathrm{X}$ & - & $\mathrm{X}$ & - \\
\hline Ingá (Inga edulis) & $\mathrm{X}$ & $\mathrm{X}$ & - & 2 & - & - & $\mathrm{X}$ & - & $\mathrm{X}$ & - \\
\hline Inajá (Attalea maripa) & $\mathrm{X}$ & $\mathrm{X}$ & $\mathrm{X}$ & 6 & - & $X$ & - & - & - & $\mathrm{X}$ \\
\hline Melancieiro (Alexa grandiflora) & $\mathrm{X}$ & - & $X$ & 2 & - & $X$ & - & - & - & $X$ \\
\hline Tatajuba (Bagassa guianensis) & $\mathrm{X}$ & - & $\mathrm{X}$ & 5 & - & $\mathrm{X}$ & - & - & $\mathrm{X}$ & - \\
\hline
\end{tabular}

maripa, Oenocarpus distichus, Stryphnodendron cf. foreroi e Bertholletia excelsa foram espécies que existiam na floresta primária. Isso se explica pelo fato de que as pastagens amostradas foram, em sua maioria, menores de 10 anos, com forte influência da vegetação inicial (MITJA et al., 2008). O babaçu (Attalea speciosa), também nativo da floresta, tem comportamento diferente do de outras espécies, com desenvolvimento, às vezes, espetacular em ambientes secundários.

Os dados apresentados neste trabalho mostram que a densidade de indivíduos por ha cresce quando a pastagem fica mais antiga, Isso se deve à maior adaptação das espécies, principalmente do babaçu, ao ecossistema da pastagem e, ou, às perturbações humanas ao longo do tempo.

\subsection{Recomendações de conservação de espécies lenhosas nas pastagens}

A conservação das árvores e palmeiras nas pastagens pode ser uma boa maneira de conservar uma biodiversidade razoável nas paisagens, além de conferir às pastagens um estatuto de área reflorestada. Ribeiro et al. (1994) sugeriram para áreas de cerrado que as espécies arbóreas possam ser conservadas para cumprir a legislação florestal que prevê áreas de 20\% de reserva nas propriedades rurais. Para a Amazônia, onde a área de reserva deve ser de $80 \%$, a conservação das árvores e palmeiras poderia também ser uma maneira de cumprir a lei.

O ideal é conservar espécies com uso múltiplo que resistem ao fogo e às drásticas condições microclimáticas das pastagens durante vários anos. As nove espécies que apareceram, simultaneamente na classe de 6 a 10 fogos e sobrevivência em mais de 10 anos de cultivo das pastagens, são as principais espécies indicadas para arborização das pastagens. Quatro apresentaram os três tipos de usos citados (sombra, frutos e madeira): piquiá, castanheira, babaçu e bacaba (Tabela 5). Cinco outras espécies têm somente um ou dois dos três principais tipos de uso, mas apresentam também multiúso: tucumã, jacarandá, pente-de- macaco, pau-preto e taperebá. As 12 outras espécies que aparecem na lista são consideradas não muito resistentes, mas podem também ser preconizadas para arborização de pastagens.

Para chegar a pastagens arborizadas, os agricultores têm três caminhos que podem ser usados de maneira complementar, o primeiro é a conservação no momento do desmatamento inicial, de indivíduos adultos ou jovens das espécies citadas anteriormente e que estão

Revista Árvore, Viçosa-MG, v.35, n.4., p.919-930, 2011 
inicialmente presentes na floresta; o segundo são o reconhecimento e a conservação na pastagem de rebrotos dessas espécies para que elas consigam crescer e se tornar adultas; e o terceiro é o plantio dessas espécies. Esse último caminho implica investimento em dinheiro e mão de obra maior que os dois outros. Além disso, pesquisas complementares deveriam ser feitas para ver se essas espécies podem ser implantadas com sucesso nas pastagens a partir de mudas.

Ainda precisa ser avaliado quantas espécies e, ou, número de indivíduos ou que cobertura por hectare seriam necessários, de um lado, para que a forrageira não fique prejudicada e, de outro lado, para que essa pastagem arborizada possa ser considerada como um reflorestamento pelos órgãos fiscalizadores das propriedades rurais.

\section{AGRADECIMENTOS}

Ao Laboratório Socioagronômico do Tocantins (LASAT), pelo apoio logístico no trabalho de campo e tratamento do material botânico; ao Institut Français de la Biodiversité (IFB), pelo apoio financeiro durante a realização do trabalho; ao Institut de Recherche et de Développement (IRD), pela concessão da bolsa de iniciação científica ao primeiro autor; aos agricultores, pela receptividade em seus estabelecimentos; e ao Sr. Deurival da Costa Carvalho e Sr. Manuel Cordeiro, pela dedicação, boa vontade e pelo bom humor, no campo e no herbário, respectivamente.

\section{REFERÊNCIAS}

ALMEIDA, M. F. Caracterização agrometeorológica do município de Marabá - PA. 2007. 77f. Monografia (Trabalho de Conclusão de Curso em Agronomia) Universidade Federal do Pará, Marabá, 2007.

Alves, R. N. B.; HOMMA, A. K. O. Pecuária Versus diversificação da produção nos projetos de assentamentos no sudeste paraense. Belém: Embrapa Amazônia Oriental, 2004. p.1-6. (Comunicado Técnico, 97).

ANDRADE, C. M. S.; VALENTIM, J. F.; CARNEIRO, J. C. Árvores de Baginha (Stryphnodendron guianense (Aubl.) Benth.) em ecossistemas de pastagens cultivadas na Amazônia Ocidental. Revista Brasileira de Zootecnia, v.31, n.2, p.574-582, 2002.
CASTRO, C. R. T.; LEITE, H. G.; COUTO, L. Sistemas silvipastoris no Brasil: potencialidades e entraves. Revista Árvore, v.20, n.4, p.575-582, 1996.

DIAS FILHO, M. B.. Degradação de pastagens: processos, causas e estratégias de recuperação. 2.ed. Belém: Embrapa Amazônia Oriental, 2005.

DIAS-FILHO, M. B.; ANDRADE, C. M. S. Pastagens no ecossistema do trópico úmido. In: SIMPÓSIO SOBRE PASTAGENS NOS ECOSSISTEMAS BRASILEIROS: alternativas vaiáveis visando a sustentabilidade dos ecossistemas de produção de ruminantes nos diferentes ecossistemas, 2005, Goiânia. Anais...Goiânia: SBZ, 2005. p.95-104.

EVANGELISTA, A. R.; LIMA, J. A. Recuperação de pastagens degradadas. Disponível:<http://www.editora.ufla.br/Boletim/ pdfextensao/bol83.pdf>. Acesso: 20 out. de 2006.

FRANKE, L. I. Principais usos e serviços de árvores e arbustos promissores que ocorrem em pastagens no Estado do Acre. Rio Branco: Embrapa Acre, 1999. 6p.(Embrapa Acre. Comunicado Técnico, 106).

GOMES, I. Sustentabilidade social e ambiental na agricultura familiar. Revista de Biologia e Ciências da Terra, v.5, n.1, p.1-17, 2004.

HARVEY, C. A.; HARBER, W. A. Remnant trees and the conservation of biodiversity in Costa Rican pastures. Agroforestry Systems, v.44, n.1, p.37-68, 1998.

HERINGER, I.; JACQUES, A. V. Á. Adaptação das plantas ao fogo: enfoque na transição floresta campo. Ciência Rural., v.31, n.6, p.1085-1090, 2001.

IBGE - Dados do Censo Agropecuário , Rio de Janeiro, p.1-146, 2006. Disponível em: $<$ www.Ibge.gov.br $>$, acessado dia 28 de jan. de 2008.

JESUS, E. C.; SCHIAVO, J. A.; FARIA, S. M. Dependência de micorrizas para a nodulação de leguminosas arbóreas tropicais. Revista Árvore, v.29, n.4, p.545-552, 2005.

Revista Árvore, Viçosa-MG, v.35, n.4, p.919-930, 2011 
KitAmurA, P. C. A Amazônia e o desenvolvimento sustentável. Brasília: Embrapa-SPI, 1994. 182p.

LASAT. Desmatamento \& Agricultura na Região de Marabá. Convênio FATALASAT Projeto DFID-FATA, 1998.

MARGULIS, S.. Causas do desmatamento da Amazônia Brasileira. -Brasília: Banco Mundial - Brasil, 2003. 100p.

MEDEIROS, M. B.; MIRANDA, H. S. Mortalidade pós-fogo em espécies lenhosas de campo sujo submetido a três queimadas prescritas anuais. Revista Acta Botânica Brasileira, v. 19, n.4, p.493-500, 2005.

MICHELOTTI, F.; RODRIGUES, F. N. C. V. Desafios para a sustentabilidade ecológica integrada a trajetórias de estabilização da agricultura familiar na Região de Marabá.

Novos Cadernos NAEA/UFPA, v.5, n.1, p.73-103, 2004.

MITJA, D. \& FERRAZ, I. Establishment of babassu in pastures in Pará, Brazil. Palms, v.45, n.3, p.138-147, 2001.

MITJA, D.; ROBERT, P. Renovação das pastagens por agricultores familiares na Amazônia: o caso de Santa Maria, PA.

Cadernos de Ciência \& Tecnologia, v.20, n.3, p.453-493, 2003.

MITJA, D. et al. Plant species richness and floristic composition change along a rice-pasture sequence in subsistence farms of Brasilian Amazon, influence on the fallows biodiversity (Benfica, State of Pará). Agriculture

Ecosystems and Environment, v.124, n.1, p.72-84, 2008.
PINHEIRO, C. U. B.; SANTOS, V. M.; FERREIRA, F. R. Usos de subsistência de espécies vegetais na Região da Baixada Maranhense. Amazônia Ciência \& Desenvolvimento, v.1, n.1, p.235-250, 2005.

REIS, R. B. A Influência das plantas invasoras, densidade de plantio, valor cultural de sementes de Brachiaria brizantha, na formação de pastagens no sudeste paraense. 2006. $80 \mathrm{f}$. Monografia (Trabalho de Conclusão de Curso em Agronomia) - Universidade Federal do Pará, Marabá, 2006.

RIBEIRO, J. F. et al. Espécies arbóreas de usos múltiplos da região do cerrado: caracterização botânica, uso potencial e reprodução. In: CONGRESSO BRASILEIRO SOBRE SISTEMAS AGROFLORESTAIS, 1., 1994, Porto Velho. Anais...Porto Velho: Embrapa - CPAF, 1994.

RIBEIRO, C. F. A. et al. Expansão da Pecuária de Bovinos e Desafios de Sustentabilidade da Atividade na Amazônia Legal. III Workshop Brasil - Japão em Energia, Meio Ambiente e Desenvolvimento Sustentável. 2006 Disponível:http://www.cori.rei.unicamp.br. Acesso em: 24 de Jan. 2007.

RODRIGUES, M. S. O Sistema de criação de bovinos no assentamento agro-extrativista praialta piranheira: importância e diversidade. 2005. 88f. Monografia (Trabalho de Conclusão de Curso em Ciências Agrárias) - Universidade Federal do Pará, Marabá, 2005.

SHANLEY, P.; MEDINA, G.. Frutíferas e plantas úteis na vida amazônica. Belém: CIFOR, Imazon, 2005. 300p.

VEIGA, J. B. et al. Sistemas Silvipastoris na Amazônia Oriental. Belém: Embrapa Amazônia Oriental, 2000. 62p. (Embrapa Amazônia Oriental. Documentos, 56). 